une revue Gallia

Rhône-Alpes | 2009

\title{
Aubenas
}

Bourdary Saint-Pierre

\section{Éric Durand}

\section{(2) OpenEdition}

Édition électronique

URL : http://journals.openedition.org/adlfi/3393

ISSN : 2114-0502

Éditeur

Ministère de la culture

\section{Référence électronique}

Éric Durand, «Aubenas », ADLFI. Archéologie de la France - Informations [En ligne], Rhône-Alpes, mis en ligne le 01 mars 2009, consulté le 19 avril 2019. URL : http://journals.openedition.org/adlfi/3393

Ce document a été généré automatiquement le 19 avril 2019

(c) Ministère de la Culture et de la Communication, CNRS 


\title{
Aubenas
}

\author{
Bourdary Saint-Pierre
}

\author{
Éric Durand
}

Identifiant de l'opération archéologique : 1040

Date de l'opération : 2009 (EX)

1 Cette étude d'impact archéologique (61 sondages mécaniques) réalisée sur les 5,5 ha de l'emprise de la future zone d'activités de Bourdary a également permis de compléter et de renouveler la connaissance de ce territoire depuis la Préhistoire.

2 Sur le plan géomorphologique, 19 sondages implantés sur la moitié orientale de l'emprise ont permis de reconnaître le terrain naturel. Il est représenté par la terrasse de l' Ardèche dont le lit actuel est situé à $400 \mathrm{~m}$ à l'est du site. Cette basse terrasse würmienne apparaitt sous un recouvrement sédimentaire variant selon les secteurs entre -0,6 $\mathrm{m}$ et -2,2 $\mathrm{m}$. Deux zones d'affleurement du substrat ont été mises au jour et cartographiées. La principale située dans la partie médiane du site est conservée sous la forme d'une butte d'environ 1,4 ha. Son toit est irrégulier et ses limites sont représentées dans quatre sondages par une incision nette du dépôt de galets et de graviers (granit, grès, calcaire et basalte) par le méandre d'un paléochenal de l'Ardèche. Orienté globalement nord-sud, la largeur de ce dernier varie d'après les sondages entre $70 \mathrm{~m}$ au nord et $110 \mathrm{~m}$ ) au sud. Outre la présence ponctuelle de mobilier céramique remanié dans ses horizons alluviaux (âge du Fer et période gallo-romaine), l'ensemble de ce secteur (environ 4 ha) n'a livré aucun vestige archéologique conservé in situ.

3 Excepté la mise au jour d'un artefact isolé attribuable sous réserve au Paléolithique supérieur, la Préhistoire ancienne n'est pas représentée. Quelques indices de fréquentation attribuables à la fin du Néolithique ont été répertoriés dans 3 sondages localisés au nord-ouest du site. Ils apparaissent entre $-1,2 \mathrm{~m}$ et $-1,7 \mathrm{~m}$ dans un horizon limoneux profond caractéristique de la séquence stratigraphique inférieure du secteur occidental. 
4 Les premiers vestiges conservés en place ont pu être datés de La Tène finale ( $\mathrm{I}^{\mathrm{er}} \mathrm{s}$. avant notre ère) et localisés au nord-est du site (parcelle 1467). Cette occupation contemporaine des sites de VIlle $\mathrm{s}$. et de Jastres est matérialisée principalement par la présence de céramiques, quelques rares restes fauniques et une monnaie de la fin de l'âge du Fer. L'ensemble de ce mobilier est réparti dans sept tranchées sur environ $3200 \mathrm{~m}^{2}$. Deux d'entre elles ont permis de mettre au jour des restes mal conservés d'habitat (mur-solin en galets). Apparus à $-1 \mathrm{~m}$, ils témoignent de l'existence d'un petit établissement rural.

5 Le fait remarquable de cette opération concerne la mise au jour d'un site gallo-romain ( ${ }^{\text {er }}$

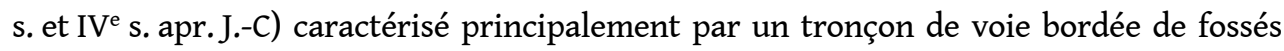
accompagnée de structures bâties périphériques conservées sur une superficie avoisinant les $3000 \mathrm{~m}^{2}$. Cette découverte confirme et complète les données archéologiques du site voisin de Saint-Pierre-sous-Aubenas localisé $500 \mathrm{~m}$ plus à l'est. La portion de voie, orientée globalement selon un axe est-ouest, a été reconnue dans trois sondages implantés dans le même secteur nord-est que le site laténien tardif. Suivie sur $33 \mathrm{~m}$ et conservée sur $3 \mathrm{~m}$ à $3,3 \mathrm{~m}$ de largeur, elle présente entre un léger pendage ouest-est $(1,2 \%)$. Les deux fossés adjacents présentent des largeurs variant de $0,9 \mathrm{~m}$ à $2,7 \mathrm{~m}$ au nord et $1,6 \mathrm{~m}$ au sud. Sa bande de roulement, au profil transversal bombé ou en creux est composée d'un seul niveau de cailloutis d'empierrement reposant sur un bloc (module moyen $0,10 \mathrm{~m}$ à $0,25 \mathrm{~m}$ ). Malgré la présence de quelques ornières, aucun niveau de recharge (réfection) n'a été observé, La faible puissance stratigraphique de cette structure empierrée (entre $0,15 \mathrm{~m}$ et $0,3 \mathrm{~m}$ au total) et de ses fossés latéraux $(0,28 \mathrm{~m}$ à $0,36 \mathrm{~m}$ ) et l'absence de réfection (recharge et/ou curage) témoignent d'une durée de vie assez courte dont la datation est difficile à préciser. Sa position chrono-stratigraphique est calée entre le scellement d'un remblai d'abandon daté des Ille $^{e}$ s.-IV ${ }^{e}$ s. apr. J.-C., le creusement partiel d'un horizon antique (fossé sud) et un niveau d'occupation de la fin $\mathrm{du} \mathrm{I}^{\mathrm{er}} \mathrm{s}$. avant notre ère. Seule la présence isolée dans le remplissage supérieur du fossé méridional d'un col d'amphore gauloise type G1 (ler s.-début Ille s.) apporte quelques précisions.

6 Quatre autres structures sont situées au sud de la voie. Orientés sur le même axe que la voie, deux tronçons d'un même mur ont été mis au jour à $11 \mathrm{~m}$ de cette dernière. Son installation en tranchée étroite recoupe l'horizon tardo-laténien. Un remblai-dépotoir daté du IV s. apr. J.-C. est installé contre ses parements. Une seconde construction mal conservée est localisée à $5 \mathrm{~m}$ au sud de la voie. Il s'agit probablement d'une première assise de fondation d'un mur dont l'élévation a totalement disparu. Malgré une orientation différente des précédentes structures, son attribution à l'Antiquité tardive semble avérée. L'ultime construction antique mise au jour est située à $30 \mathrm{~m}$ au sud de la voie. Orientée sud-ouest - nord-est, elle est composée comme les autres d'une seule assise de galets et de quelques blocs de calcaires (dont un moellon équarri) recoupant un horizon argilo-limoneux incluant des fragments de tegulaeet de céramique non tournée. Au nord du site, un fonds de fossé a été suivi uniquement lors du décapage mécanique sur un axe de $8 \mathrm{~m}$ (nord-sud). Sa largeur d'ouverture varie entre $0,6 \mathrm{~m}$ et $1,2 \mathrm{~m}$. Le comblement de cette structure (drain ?) conservé sur environ $0,3 \mathrm{~m}$ a livré du mobilier céramique et faunique antique associé à quelques éléments laténiens résiduels.

7 Les autres vestiges mis au jour concernent la période contemporaine et la mise en culture de ce terroir au XIX $\mathrm{s}$. Ainsi 12 drains ont été répertoriés sur l'ensemble de l'emprise. L'exploitation agricole de ce secteur est attestée enfin par la présence de deux chablis rubéfiés (S18 et 36). 
INDEX

operation expertise (EX)

Index géographique : Rhône-Alpes, Ardèche, Aubenas

Thèmes : amphore gauloise, céramique, dépotoir, faune, fossé, habitat, habitat rural, monnaie, tuile

Index chronologique : Âge du Fer, Antiquité, Ier siècle apr. J.-C., IIe siècle apr. J.-C., IIIe siècle apr. J.-C., IVe siècle apr. J.-C., La Tène III, Néolithique, Paléolithique supérieur

\section{AUTEUR}

ÉRIC DURAND 